\title{
KERJASAMA TIM MEMEDIASI DAMPAK KEPEMIMPINAN TRANSFORMASIONAL DAN TRANSAKSIONAL TERHADAP KINERJA KERJA
}

\author{
Hanna Fransiska \\ Sunjoyo \\ Alumnus Fakultas Ekonomi Universitas Kristen Maranatha, Bandung, Indonesia \\ Fakultas Ekonomi Universitas Kristen Maranatha, Bandung, Indonesia \\ Email: hanna.fransiska@ymail.com; sunjoyo@eco.maranatha.edu
}

Submitted: Mar 22, 2017; Reviewed: Apr 7, 2017; Accepted: Nov 20, 2018

\begin{abstract}
The purposes of this study are: a) to examine whether transformational and transactional leadership positively affect teamwork positively; b) to examine whether teamwork directly and positively affects job performance; c) to examine whether transformational and transactional leadership directly and positively affect job performance. A sample of this study is consisted of 121 leaders who work in 17 private companies operating in the city of Bandung. Two of five hypotheses were supported, which hypotheses were tested using Structural Equation Modeling (SEM). There are some findings of this study. First, transformational leadership positively affects teamwork, but transactional leadership does not affect it. Second, teamwork does not affect job performance. Third, transformational leadership directly affects job performance, but transactional leadership does not affect it. The implications of this research was discussed as well as suggestions for future research.
\end{abstract}

Keywords: Job Performance; Leadership Beliefs Inventory (LBI); Practice Environment Survey; Teamwork; Transactional Leadership; Transformational Leadership

\section{PENDAHULUAN}

Pada dasarnya di dunia ini akan berubah mulai dari ilmu pengetahuan, teknologi, cara kerja sehingga manusia dituntut untuk menghasilkan kinerja kerja yang lebih tinggi ataupun lebih baik lagi (Noviansyah, 2011). Kinerja juga dapat digambarkan dengan seberapa baik seseorang melakukan tugas yang berhubungan dengan pekerjaan (Caillier, 2010). Kinerja juga menentukan kualitas kehidupan organisasi dan keefektifan (Giri \& Kumar, 2010). Selain itu, kinerja juga menciptakan produk atau service yang unik yang membawa perubahan dan yang bermanfaat (Vidal \& Marle, 2008). Kinerja yang lebih baik dapat membawa peningkatan kepada hasil usaha (Pushpakumari, 2008). Dalam organisasi, sebuah faktor dasar untuk peningkatan kinerja kerja ialah komunikasi antara karyawan dan penyelia, individual harus jelas memahami tugas mereka dan posisi masingmasing, dan karyawan harus mengetahui harapan penyelia (Giri \& Kumar, 2010).
Kinerja sudah bertambah dikenal sebagai dasar dari tugas yang sulit dan rumit yang tidak diperlukan dan yang tidak gampang ditangani oleh satu orang (Catchpole et al., 2008). Banyak organisasi yang semakin beralih ke fungsi tim lintas sebagai cara yang efisien untuk memecahkan masalah yang kompeks (Wang \& $\mathrm{He}, 2008)$. Penggunaan tim telah berulang kali digambarkan sebagai mempromosikan kreativitas tim yang lebih besar, proses pengambilan keputusan yang lebih cepat, tim dan pembelajaraan organisasi yang lebih tinggi, peningkatan kinerja, dan meningkatnya koordinasi antar unit organisasi jika terpisah (Catchpole et al., 2008). Di dalam tim, pemimpin memainkan peran penting dalam menentukan hasil tim (Nonose, Kanno, \& Furuta, 2012). Untuk menjadi pemimpin terbaik perlu melibatkan dan berkolaborasi dengan orang lain - seorang pemimpin tidak dapat memimpin seorang diri (Kouzes \& Posner, 2016). 
Para pemimpin menjadi hebat bukan karena kekuasaan mereka, tetapi karena kemampuan mereka memberdayakan orang lain (Maxwell, 2018). Untuk dapat memberdayakan orang lain, dibutuhkan para pemimpin yang kuat dalam keteladanan (Kouzes \& Posner, 2016). Kekuatan para pemimpin transformasional berasal dari kemampuan mereka menstimulasi dan menginspirasi orang lain untuk menghasilkan pekerjaan yang luar biasa (Lai, 2011). Berbeda dengan kepemimpinan transaksional yang lebih mementingkan pertukaran yang bersifat ekonomis, politis, dan psikologis (Indrapradja, 2014). Oleh sebab itu, terdapat beberapa tujuan studi ini. Pertama, untuk mengetahui apakah kepemimpinan transformasional, transaksional memengaruhi kerja sama tim secara langsung dan kinerja kerja secara tidak langsung. Kedua, untuk mengetahui apakah kepemimpinan transformasional, transaksional memengaruhi kinerja kerja secara langsung. Ketiga, untuk mengetahui apakah kerja sama tim memengaruhi kinerja kerja secara positif.

\section{TINJAUAN PUSTAKA}

\section{Kepemimpinan Transformasional}

Kepemimpinan transformasional merupakan sebuah gaya kepemimpinan yang digunakan oleh manajer jika ia ingin memperluas batasanbatasan kelompok dan telah melampaui kinerja status quo atau mencapai serangkaian tujuan organisasional yang sama sekali baru (O'Leary, 2001). Avolio, Bass, \& Jung (1999) mengemukakan bahwa kepemimpinan transformasional sebagai kepemimpinan yang mendorong pengikut untuk mengembangkan mereka dengan cara melibatkan setiap individual dan tim untuk kuantitas output produksi. Berbagai dimensi kepemimpinan transformasional telah diidentifikasi dalam beberapa literatur (Avolio, Bass, \& Jung, 1999), yakni idealized attributes and behaviors, inspirational motivation, individual consideration, and intellectual stimulation. Namun berbeda dangan dimensi-dimensi kepemimpinan transformasional yang diperkenalkan oleh beberapa peneliti (Rosenbach \& Sashkin, 2007; Sashkin \& Sashkin, 2003) yang terdiri atas berbagai perilaku (communications, credible, caring and enabling leadership) dan karakteristik (confident, follower-centered, visionary, and culturebuilding leadership).

\section{Kepemimpinan Transaksional}

Seltzer \& Bass (1990) mengemukakan kepemimpinan transaksional adalah kepemimpinan di mana pemimpin menentukan apa yang harus dikerjakan oleh karyawan agar mereka dapat mencapai tujuan mereka sendiri atau organisasional dan membantu karyawan agar memeroleh kepercayaan dalam mengerjakan tugas tersebut. Kepemimpinan transaksional mengacu pada pertukaran hubungan antara pemimpin dan pengikut untuk memenuhi kepentingan diri mereka sendiri (Avolio, Bass, \& Jung, 1999). Berbagai dimensi kepemimpinan transaksional menurut Bass (1990) yakni, Contingent reward, laissez faire, managementby-exception passive and active. Adapula dimensi kepemimpinan transaksional lainnya, yaitu capable management and reward equity (Rosenbach \& Sashkin, 2007).

\section{Kerja sama Tim}

Kerjasama tim merupakan kelompok yang usaha-usaha individualnya menghasilkan kinerja lebih tinggi daripada jumlah masukan individual (Robbins \& Judge, 2008). Menurut Bachtiar (2004) kerjasama merupakan sinergisitas kekuatan dari beberapa orang dalam mencapai satu tujuan yang diinginkan dan menyatukan kekuatan ide-ide yang akan mengantarkan pada kesuksesan. Menurut Cummings \& Worley (2005) dimensi kerja sama tim yaitu Goal clarity, task structure, group composition, group norms, team functioning.

\section{Kinerja Kerja}

Menurut Simamora (2004), kinerja kerja adalah kadar pencapaian tugas-tugas yang membentuk pekerjaan karyawan dan merefleksikan seberapa baik karyawan memenuhi persyaratan sebuah pekerjaan. Mathis \& Jackson (2006) menjelaskan ada tiga faktor utama yang mempengaruhi kinerja kerja karyawan adalah kemampuan individual untuk melakukan pekerjaan tersebut, tingkat usaha yang dicurahkan dan dukungan organisasional yang diterimanya.

\section{Hubungan Antar konstruk Penelitian \\ Hubungan antara Kepemimpinan Transformasional dan Kerjasama Tim}

Kark, Shamir, \& Chen (2003) menunjukkan bahwa kepemimpinan transformasional dapat memberi pengaruh kepada pengikut dengan menghubungkan konsep mereka tentang diri sendiri untuk misi organisasional atau kelompok dan menangani dan memodifikasi nilai-nilai 
mereka dan harga diri. Pemimpin transformasional memberikan inspirasi kepada bawahan untuk memusatkan perhatian pada tujuan bersama bukan lagi sekedar kepentingan pribadi melainkan kepentingan bersama (Natalius, 2011). Kepemimpinan transformasional membuat pengikut merasa diperhatikan, didengarkan sehingga pengikut diberi kebebasan dalam berkembang sehingga dapat menjalani kerjasama tim yang baik (Nonose et al., 2012). Dalam beberapa penelitian mengatakan bahwa kepemimpinan transformasional membawa dampak positif untuk kerjasama tim (Kark, Shamir, \& Chen, 2003; Natalius, 2011; Yang, Wu \& Huang, 2013), maka hipotesis yang diajukan adalah:

$H_{l}$ : Kepemimpinan transformasional memengaruhi kerjasama tim secara positif.

\section{Hubungan antara Kepemimpinan Transaksional dan Kerjasama Tim}

Kepemimpinan transaksional menekankan pada transaksi atau pertukaran yang terjadi antar pemimpin, rekan kerja dan bawahannya (Keegan \& Hartog, 2004). Pertukaran ini merupakan hasil diskusi pemimpin transaksional sehingga karyawan dapat melakukan kerjasama tim agar mendapatkan hasil yang telah ditawarkan (Indrapradja, 2014). Dalam beberapa penelitian (Keegan \& Hartog, 2004; Natalius, 2011; Yang et al., 2013) mengemukakan bahwa kepemimpinan transformasional memengaruhi secara positif terhadap kerjasama tim, sehingga hipotesis yang diajukan adalah:

$\mathrm{H}_{2}$ : Kepemimpinan transaksional memengaruhi kerjasama tim secara positif.

\section{Hubungan antara Kerjasama tim dan Kinerja Kerja}

Kerjasama merupakan salah satu mode interaksi yang di mana pelaku dengan aktif menyeimbangkan dan menyatupadankan/menyamaratakan perilaku mereka (Engestrom et al., 1997). Kerjasama dapat membuat kinerja kerja meningkat dikarenakan kekompakan tim dan keserasian perilaku mereka, tim yang efektif berpengaruh pada kinerja kerja dapat berasal dari komunikasi tim, kolaborasi, dan kekompakan (Kendra \& Taplin, 2004). Beberapa studi telah menyarankan bahwa kerja tim memiliki peran memediasi pada hubungan antara gaya kepemimpinan dan kinerja kerja (Kotlarsky \& Oshri, 2005; Poernomo, 2006; Marpaung, 2014; Thamain, 2004; Wang, Chou, \& Jiang, 2005).
Berdasarkan beberapa hasil penelitian tersebut, maka hipotesis yang diajukan adalah:

$\mathrm{H}_{3}$ : Kerjasama tim memengaruhi kinerja kerja secara positif.

\section{Hubungan antara Kepemimpinan Transformasional dan Kinerja kerja}

Kepemimpinan transformasional merupakan pemimpin yang mencurahkan perhatian pada halhal dan kebutuhan pengembangan dari masingmasing pengikut, sehingga pemimpin transformasional dapat mengubah kesadaran para pengikut akan persoalan-persoalan dengan membantu mereka memandang masalah lama dengan cara-cara baru (Rakhmawati \& Darmanto, 2014). Pemimpin transformational dapat menciptakan kondisi dalam organisasional yang mendukung dan mempertahankan kinerja kerja (Davies, 2005). Temuan berbagai penelitian menunjukkan bahwa kepemimpinan transformasional berpengaruh positif terhadap kinerja kerja (Bass et al., 2003; Judge \& Piccolo, 2004; Nugroho, 2011; Pane \& Astuti, 2009; Rakhmawati \& Darmanto, 2014; Yang et al., 2013), maka hipotesis yang diajukan adalah:

$\mathrm{H}_{4}$ : Kepemimpinan transformasional memengaruhi kinerja kerja secara positif.

\section{Hubungan antara Kepemimpinan Transaksional dan Kinerja Kerja}

Pemimpin transaksional memanfaatkan penghargaan dan hukuman untuk memimpin pengikut dan memperoleh hasil yang diinginkan (Natalius, 2011). Pemimpin transaksional juga memanfaatkan hubungan timbal balik yang dapat dilakukan sehingga kinerja kerja berdampak positif (Yang et al., 2013). Maka dari itu dilihat dari beberapa hasil penelitian yang menunjukan bahwa kepemimpinan transaksional memengaruhi kinerja kerja secara positif (Bass et al., 2003; Natalius, 2011; Pradana, Sunuharyo \& Hamid, 2013; Yang et al., 2013) maka hipotesis yang diajukan adalah:

$\mathrm{H}_{5}$ : Kepemimpinan transaksional memengaruhi kinerja kerja secara positif.

\section{MODEL PENELITIAN}

Berdasarkan 5 (lima) hipotesis yang diajukan di atas maka model penelitian dapat digambarkan sebagai berikut: 


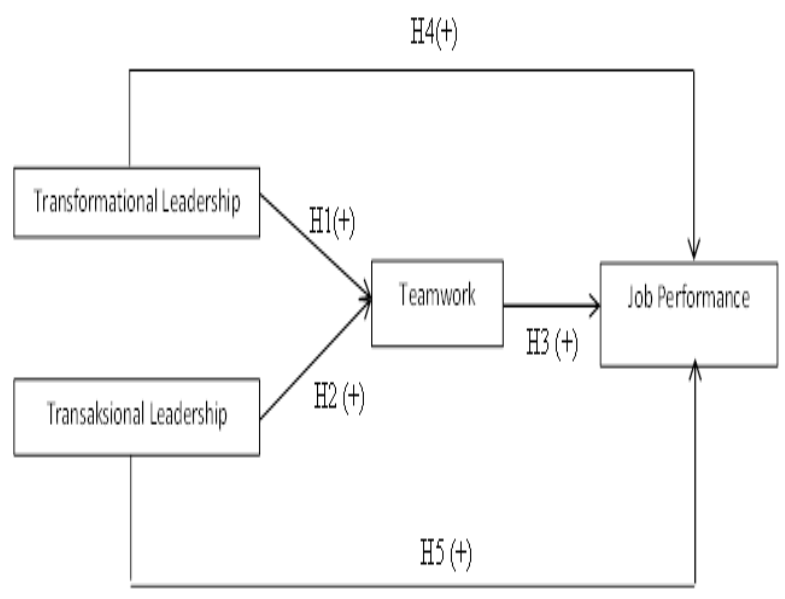

Gambar 1 Model Penelitian yang Dihipotesiskan

Sumber: Berbagai Literatur (Bass et al., 2003; Judge \& Piccolo, 2004; Kotlarsky \& Oshri, 2005; Marpaung, 2014; Natalius, 2011; Nugroho, 2011; Pane \& Astuti, 2009; Poernomo, 2006; Pradana, Sunuharyo \& Hamid, 2013; Rakhmawati \& Darmanto, 2014; Thamain, 2004; Wang et al., 2005; Yang et al., 2013)

\section{METODE PENELITIAN}

\section{Subjek dan Teknik Pengumpulan Data Riset}

Subjek penelitian ini adalah para karyawan dan pemimpin yang memberikan penilaian terhadap atasan langsungnya - minimal level penyelia pada berbagai industri di Bandung - dan atasan langsung tersebut dinilai oleh tiga rekan kerja yang dipimpinnya. Jumlah responden riset ini berjumlah 121. Teknik pengumpulan data menggunakan metoda survei - metode pengumpulan data primer dengan alat bantu kuesioner yang memberikan pertanyaanpertanyaan kepada responden secara tertulis (Sugiyono, 2012). Skala yang digunakan dalam mengukur respons subjek adalah skala Likert yang menggunakan 5 (lima) butir skala dengan interval yang sama (Sugiyono, 2012).

\section{DEFINISI OPERASIONAL VARIABEL}

Butir-butir instrumen penelitian ini untuk mengukur pengaruh kepemimpinan transformasional dan transaksional terhadap kinerja karyawan yang dimediasi oleh kerjasama tim. Dengan kepemimpinan transformasional dan transaksional sebagai variabel bebas, kinerja kerja sebagai variabel terikat dan kerjasama tim sebagai variabel mediator.
Kepemimpinan

Transformasional

dan Transaksional

Penelitian kepemimpinan transformasional dan transaksional menggunakan kuesioner leadership beliefs inventory (LBI) oleh Sashkin dan Sashkin (2003) yang terdiri atas 10 (sepuluh) butir pertanyaan. Pengukuran butir pertanyaan menggunakan skala Likert dengan rentang 1 (sangat tidak setuju) sampai 5 (sangat setuju). LBI merupakan suatu kuesioner versi pendek yang dirancang oleh Marshall Sashkin yang bekerjasama dengan Warren Bennis (Sashkin \& Sashkin, 2003), namun sangat disayangkan dalam literatur tersebut tidak dinyatakan koefisien Cronbach's alpha atas kedua konstruk ini.

\section{Kerjasama Tim}

Penelitian kerjasama tim menggunakan kuesioner practice environment survey oleh Lurie, Schultz, \& Lamanna (2011) yang terdiri atas 29 (dua puluh sembilan) butir pertanyaan, tapi dalam penelitian ini hanya diambil 5 (lima) butir pertanyaan saja dikarenakan dari 29 (dua puluh sembilan) butir pertanyaan hanya 5 (lima) butir saja yang valid dan dapat dipakai. Pengukuran butir pertanyaan menggunakan skala Likert dengan rentang rentang 1 (sangat tidak setuju) sampai 5 (sangat setuju). Koefisien Cronbach's alpha konstruk ini adalah 0,94 (Lurie et al., 2011).

\section{Kinerja Kerja}

Penelitian kinerja kerja menggunakan kuesioner job performance oleh Singh, Verbeke, \& Rhoads, seperti yang dikutip dalam Babin \& Boles (1998) yang terdiri atas 7 (tujuh) butir pertanyaan. Pengukuran butir pertanyaan menggunakan skala Likert dengan rentang 1 (sangat tidak setuju) sampai 5 (sangat setuju). Koefisien Cronbach's alpha konstruk ini adalah 0,89 (Singh et al., seperti yang dikutip dalam Babin \& Boles, 1998).

\section{Variabel Kontrol}

Variabel kontrol dalam studi ini terdiri atas 5 (lima) variabel kontrol yang dianggap memiliki hubungan erat dengan variabel utama studi ini. Variabel kontrol dalam studi ini terdiri atas: jenis kelamin ( $1=$ laki-laki; $2=$ perempuan $)$, usia (1= kurang dari 24 tahun; $2=24$ hingga kurang dari 32 tahun; $3=32$ hingga kurang dari 40 tahun; $4=40$ hingga kurang dari 48 tahun; dan 5 $=48$ tahun atau lebih $)$, jabatan $(1=$ penyelia (penyelia) dan/atau pemimpin tim; $2=$ asisten 
manajer; $3=$ manajer/general manager; $4=$ direktur/direktur utama/komisaris/owner;5 = lainnya), tingkat pendidikan $(1=$ tidak sekolah hingga SMP; 2 = SMU/Sederajat; 3 = Diploma 1 , $2,3 ; 4=\mathrm{D} 4 / \mathrm{S} 1 ;$ dan $5=\mathrm{S} 2 / \mathrm{S} 3)$, lama bekerja (1 $=1$ hingga kurang dari 2 tahun; $2=2$ hingga kurang dari 5 tahun; $3=6$ hingga kurang dari 10 tahun; $4=10$ hingga kurang dari 20 tahun; dan 5 $=20$ tahun atau lebih).

\section{HASIL DAN PEMBAHASAN}

\section{Karakteristik Responden}

Dalam studi ini, data yang dapat digunakan sebanyak 121 responden. Karakteristik responden berdasarkan jenis kelamin didominasi oleh laki-laki sebanyak 67 (54,9 persen), usia didominasi oleh responden yang relatif muda, yaitu antara 32 hingga kurang dari 40 tahun sebanyak 46 (37,7 persen), jabatan responden didominasi oleh penyelia berjumlah $68(55,7$ persen), mayoritas tingkat pendidikan responden adalah D4/S1 sebanyak 69 (56,6 persen), mayoritas responden sudah bekerja selama 10 hingga kurang dari 20 tahun sebanyak 38 (31,1 persen).

\section{Hasil Uji Outliers}

Nilai-nilai ekstrim pada hasil observasi (sampel) dibersihkan melalui uji outliers (Rantika \& Sunjoyo, 2012). Uji terhadap multivariate outliers dilakukan dengan menggunakan kriteria jarak Mahalanobis pada tingkat $p<0,001$. Jarak Mahalanobis ini dievaluasikan dengan menggunakan $t$ pada derajat bebas sebesar jumlah variabel yang digunakan dalam penelitian ini. Variabel yang digunakan dalam studi ini berjumlah 4 (empat) - Kepemimpinan transformasional, kepemimpinan transaksional, kerjasama tim dan kinerja kerja maka degree of freedom dapat dihitung dengan $d f=3-1=2$ sehingga $p<0,001$ adalah 22,326. Apabila hasil perhitungan squared mahalanobis distance > 22,326, maka data tersebut diidentifikasikan sebagai outliers. Hasil analisis data menunjukkan bahwa 121 dari 123 data lolos uji outliers.

\section{Hasil Uji Validitas dan Reliabilitas}

Pengujian validitas dan reliabilitas dalam studi ini dilakukan terhadap variabel kepemimpinan transformasional, kepemimpinan transaksional, kerjasama tim dan kinerja kerja. Uji validitas konstruk dilakukan dengan menggunakan analisis faktor atau confirmatory factor analysis $(C F A)$. Dalam pengujian validitas, nilai untuk setiap butir instrumen penelitian yang valid adalah jika setiap butir penelitian memiliki nilai factor loadings di atas 0,4 (Sunjoyo, 2013). Sementara itu, reliabilitas diukur menggunakan koefisien Cronbach's alpha ( $\alpha$ ). Sekaran dan Bougie (2010) menyatakan bahwa koefisien $\alpha$ yang kurang dari 0,6 adalah buruk, antara 0,6 dan 0,8 dapat diterima, dan di atas 0,8 adalah baik. Penelitian ini menggunakan koefisien $\alpha$ minimal 0,6 seperti yang direkomendasikan oleh Sekaran dan Bougie (2010). Tabel 1 berikut adalah ringkasan hasil analisis faktor yang dilakukan dengan bantuan program aplikasi SPSS 17.0 for Windows.

Tabel 1 Hasil Analisis Faktor untuk Setiap Konstruk dan Butir Instrumen Penelitian

\begin{tabular}{|c|c|c|c|c|c|c|}
\hline \multirow{2}{*}{ Konstruk } & \multirow{2}{*}{ Butir } & \multicolumn{4}{|c|}{ Faktor } & \multirow{2}{*}{$\alpha$} \\
\hline & & 1 & 2 & 3 & $\overline{4}$ & \\
\hline \multirow[t]{4}{*}{$\overline{\text { KTF }}$} & KTF1 & 0,889 & & & & 0,753 \\
\hline & KTF3 & 0,458 & & & & \\
\hline & KTF5 & 0,474 & & & & \\
\hline & KTF9 & 0,757 & & & & \\
\hline \multirow[t]{5}{*}{ KTA } & KTA2 & & 0,742 & & & 0,838 \\
\hline & KTA4 & & 0,729 & & & \\
\hline & KTA6 & & 0,616 & & & \\
\hline & KTA8 & & 0,81 & & & \\
\hline & KTA10 & & 0,791 & & & \\
\hline \multirow[t]{5}{*}{ KT } & KT1 & & & 0,812 & & 0,779 \\
\hline & KT2 & & & 0,696 & & \\
\hline & KT3 & & & 0,578 & & \\
\hline & KT4 & & & 0,652 & & \\
\hline & KT5 & & & 0,652 & & \\
\hline \multirow[t]{7}{*}{ KK } & KK1 & & & & 0,87 & 0,875 \\
\hline & KK2 & & & & 0,832 & \\
\hline & KK3 & & & & 0,814 & \\
\hline & KK4 & & & & 0,663 & \\
\hline & KK5 & & & & 0,436 & \\
\hline & KK6 & & & & 0,552 & \\
\hline & KK7 & & & & 0,754 & \\
\hline
\end{tabular}

\section{Keterangan:}

KTF $=$ Kepemimpinan Transformasional; $K T A=$ Kepemimpinan Transaksional; $K T=$ Kerjasama Tim; $K K=$ Kinerja Kerja

Sumber: Hasil pengolahan data

\section{Hasil Uji Statistik Deskriptif dan Korelasi Antarkonstruk Penelitian}

Pengujian nilai mean dilakukan untuk mengetahui kecenderungan persepsi responden atau sampel terhadap setiap konstruk dalam penelitian ini, sedangkan deviasi standar untuk menilai rata-rata dispersi dari responden, demikian pernyataan Santoso (2006). Sementara itu, pengujian koefisien korelasi dilakukan untuk melihat keeratan hubungan atau korelasi antarkonstruk penelitian (Harianti, Veronica, Nur, Setiawan, dan Iskandar, 2012). Dalam studi ini, pengujian deskriptif statistik dan korelasi dilakukan dengan menggunakan program aplikasi SPSS 17.0 for Windows. Tabel 2 
berikut merupakan hasil pengujian statistik deskriptif dan korelasi data penelitian ini.

Tabel 2 Hasil Uji Statistik Deskriptif dan Korelasi Antarvariabel Penelitian

\begin{tabular}{|c|c|c|c|c|c|c|c|c|c|}
\hline Variabel & II & SD & 1 & $?$ & 3 & 4 & $j$ & 6 & 1 \\
\hline 1. JK & 1,55 & 0,499 & & & & & & & \\
\hline 2. LS & 3,52 & 0,95 & 0,002 & & & & & & \\
\hline $3 . \sqrt{B}$ & 1,89 & 1,086 & 0,172 & $\cdot 0,067$ & & & & & \\
\hline 4. IP & 3,53 & 0,659 & $.0,112$ & $\cdot 0,164$ & $.231^{x}$ & & & & \\
\hline 5.LB & 3,31 & 1,189 & $\cdot 0,119$ & $.559^{\prime \prime}$ & 0.09 & $\cdot 0,134$ & & & \\
\hline 6. KIF & 3,853 & 0,3951 & 0,047 & 0,074 & 0,062 & 0,032 & 0,08 & & \\
\hline 7. KTA & 4,068 & 0,3587 & 0,054 & 0,161 & 0 & $\cdot 0,155$ & 0,121 &, $6777^{\prime \prime}$ & \\
\hline 8. KT & 4,025 & 0,3274 & 0,098 & 0,071 & 0,098 & $\cdot 0,067$ & 0,054 &, $660^{n "}$ & $.685^{18}$ \\
\hline 9. KK & 3,448 & 0,4407 & 0,009 & $\cdot 0,004$ & 0,153 & 0,117 & 0,065 & $.757^{\prime \prime}$ & $.576^{12}$ \\
\hline
\end{tabular}

Keterangan:

$M=$ Mean; $S D=$ Standard Deviations; $J K=$ Jenis Kelamin $; U S=U$ sia $; T P=$ Tingkat Pendidikan; $L B=$ Lama Bekerja $; K T=$ Kerjasama Tim $; K K=$ Kinerja Kerja; $K T F=$ Kepemimpinan Transformasional; KTA $=$ Kepemimpinan Transaksional.

$* * p<0,01 ; * p<0,05$

Sumber: Hasil Pengolahan Data

Berdasarkan Tabel 2 di atas, tingkat (mean) setiap konstruk riset menunjukkan relatif tingg dan standar deviasi menunjukkan tingkat yan: relatif rendah yaitu, kepemimpinas transformasional $(M=3,853 ; S D=0,395)$ kepemimpinan transaksional $(M=4,068 ; S D$ : $0,359)$, kerjasama tim $(M=4,025 ; S D=0,327$ dan kinerja kerja $(M=3,848 ; S D=0,441)$. Nilai nilai di atas sudah bisa dikatakan baik, tetap pihak manajemen perlu meningkatka1. kepemimpinan transformasional, kepemimpinan transaksional, kerjasama tim dan kinerja kerja pada masing-masing perusahaan. Saran untuk meningkatkan kepemimpinan transformasional, kepemimpinan transaksional, kerjasama tim dan kinerja kerja akan dibahas pada bagian saran dalam artikel ini.

\section{Hasil Uji Model Struktural}

James et al (seperti yang dikutip dalam Rantika \& Sunjoyo, 2011) menjelaskan bahwa pola "confirmatory" menunjukkan prosedur-prosedur dirancang untuk mengevaluasi utilitas hipotesishipotesis dengan pengujian fit antara model teoritis dan data empiris. Jika model teoritis menggambarkan "good fit" dengan data, maka model dianggap sebagai yang diperkuat. Sebaliknya, suatu model teoritis tidak diperkuat jika teori tersebut mempunyai suatu "poor fit" dengan data.

Tabel 3 Hasil Uji Model Struktural

\begin{tabular}{cccc}
\hline $\begin{array}{c}\text { Goodness of Fit } \\
\text { Index }\end{array}$ & $\begin{array}{c}\text { Syarat yang Harus } \\
\text { Dipenuhi }\end{array}$ & $\begin{array}{c}\text { Hasil Perhitungan } \\
\text { Model }\end{array}$ & Keterangan \\
\hline$D f$ & Positif & 183 & Baik \\
Probability & $>0,20$ & 0 & Marginal \\
$\chi^{2}$ statistic & $\geq 0,05$ & 481,187 & Baik \\
CMIN/DF & $\leq 3,00$ & 2,629 & Baik \\
NFI & $\geq 0,90$ & 0,711 & Marginal \\
$R F I$ & $\geq 0,90$ & 0,635 & Marginal \\
IFI & $\geq 0,90$ & 0,799 & Marginal \\
TLI & $\geq 0,90$ & 0,738 & Marginal \\
CFI & $\geq 0,90$ & 0,792 & Marginal \\
RMSEA & $0,05-0,08$ & 0,116 & Marginal \\
\hline
\end{tabular}

Keterangan:

$d f=$ degree of freedom; $\chi^{2}=$ chi-square $; C M I N / D F=$ The Minimum Sample Discrepancy Function/degree of freedom; $N F I=$ Normed Fit Index; TLI = Tucker Lewis Index; CFI = Comparative Fit Index; RMSEA $=$ The Root Mean Square Error of Approximation

Sumber: Hasil pengolahan data

Besar kemungkinan hasil goodness of fit measures yang marginal ini adalah disebabkan karena sampel kurang memenuhi syarat, yaitu sebaiknya berkisar antara 200-500 jika menggunakan alat analisis structural equation modeling (SEM) (Hair et al., 1998).

Hipotesis akan didukung apabila semua koefisien bernilai positif dan signifikan pada tingkat $p<0,05$. Tingkat signifikansi tersebut diuji dengan membandingkan nilai critical ratio $(C R)$ standardized regression weights pada output pengujian model pengukuran AMOS dan nilai $t$-tabel (satu sisi) pada $d f=183$, yaitu sebesar 1,645. Hipotesis didukung apabila nilai $C R$ pada standardized regression weights $\geq$ 1,645. Peneliti menguji hipotesis dengan SEM dengan menggunakan aplikasi Analysis of Moment Structures versi 21 (AMOS v.21). 
Tabel 4 Hasil Pengujian Hipotesis

\begin{tabular}{cccccc}
\hline Hipotesis & $\begin{array}{c}\text { Hubungan } \\
\text { Struktural }\end{array}$ & $\begin{array}{c}\text { Regression } \\
\text { Weights } \\
(\gamma)\end{array}$ & $\begin{array}{c}\text { Critical } \\
\text { Ratio } \\
(\text { CR })\end{array}$ & $\begin{array}{c}\text { Probability } \\
(\boldsymbol{p})\end{array}$ & Keterangan \\
\hline H1 & KT $<-$ KTF & 0,243 & 2,073 & 0,038 & Didukung \\
H2 & KT $<-$ KTA & 0,225 & 1,111 & 0,266 & Tidak didukung \\
H3 & KK $<-$ KT & 0,499 & 0,93 & 0,352 & Tidak didukung \\
H4 & KK <-- KTF & 0,598 & 2,244 & 0,025 & Didukung \\
H5 & KK $<-$ KTA & 0,447 & $-1,126$ & 0,26 & Tidak didukung \\
\hline
\end{tabular}

Keterangan:

* $\quad C R \geq 1,645 ; \quad K T F=\quad$ Kepemimpinan

Transformasional; $\quad K T A=$ Kepemimpinan

Transaksional; $K T=$ Kerjasama Tim $; K K=$ Kinerja Kerja

Sumber: Hasil pengolahan data

Berdasarkan Tabel 4 di atas yang menunjukkan bahwa Hipotesis 1 didukung $(\gamma=0,243 ; p<$ 0,05). Hal ini menunjukkan bahwa kepemimpinan transformasional memengaruhi kerjasama tim secara positif. Hasil temuan ini mengkonfirmasi beberapa studi sebelumnya (Natalius, 2011; Yang et al., 2013) yang juga mengatakan bahwa kepemimpinan transformasional memengaruhi kerjasama tim secara positif. Dengan demikian, perusahaanperusahaan perlu memberikan perhatian terhadap cara memimpin dalam perusahaan untuk menciptakan kerjasama tim yang baik. Berikut ini adalah beberapa implikasi praktis yang dapat dilakukan oleh para pemimpin perusahaan untuk mengembangkan para pemimpin transformasional yang mampu (Bass \& Avolio, 1995; Bass \& Avolio, 2002):

- Membangun kepercayaan atas diri para pengikut.

- Bertindak penuh integritas.

- Menginspirasi orang lain.

- Melakukan coaching kepada orang lain.

- Memicu pemikiaran inovatif.

Hipotesis 2 tidak didukung $(\gamma=0,225 ; p$

$>$ 0,05). Hal ini menunjukkan bahwa kepemimpinan transaksional tidak memengaruhi kerjasama tim secara positif. Hasil temuan ini tidak mengkonfirmasi beberapa studi sebelumnya (Natalius, 2011; Yang et al., 2013) yang mengatakan bahwa kepemimpinan transaksional memengaruhi kerjasama tim secara positif. Hasil temuan ini tidak didukung karena kepemimpinan transaksional cenderung mengawasi bawahan dengan ketat dan segera melakukan tindakan korektif apabila muncul penyimpangan, kekeliruan, atau kesalahan jadi bawahan akan sulit dalam bekerjasama dan merasa tidak ada dukungan karena pengawasan yang begitu ketat (Sonni, 2013).

Hipotesis 3 tidak didukung $(\gamma=0,499 ; p>$ 0,05). Hal ini menunjukkan bahwa kerjasama tim tidak memengaruhi kinerja kerja secara positif. Hasil temuan ini tidak mengkonfirmasi beberapa studi sebelumnya (Kotlarsky \& Oshri, 2005; Marpaung, 2014; Poernomo, 2006; Thamain, 2004; Wang et al., 2005; Yang et al., 2013) yang mengatakan bahwa kerjasama tim memengaruhi kinerja kerja secara positif. Hasil penelitian ini tidak didukung karena tidak semua anggota tim memiliki persepsi, ketaatan, kepatuhan dan kegairahan yang sama sehingga hasil yang diharapkan tidak sesuai dan berdampak pada kinerja (Marpaung, 2014).

Hipotesis 4 didukung $(\gamma=0,598 ; p<$ 0,05). Hal ini menunjukkan bahwa kepemimpinan transformasional memengaruhi kinerja kerja secara positif. Hasil temuan ini mengkonfirmasi beberapa studi sebelumnya (Bass et al., 2003; Judge \& Piccolo, 2004; Nugroho, 2011; Pane \& Astuti, 2009; Rakhmawati \& Darmanto, 2014; Yang et al., 2013) yang juga mengatakan bahwa kepemimpinan transformasional memengaruhi kinerja kerja secara positif. Berikut ini adalah beberapa hal yang dapat dilakukan oleh para pemimpin perusahaan untuk membangun berbagai karakteristik kepemimpinan transformasional yang (Rosenbach \& Sashkin, 2007):

- Mempunyai dan mamperlihatkan kepercayaan diri, serta mampu secara bertahap membuat para pengikut merasa, berpikir, dan bertindak dalam kepercayaan diri yang sama.

- $\quad$ Lebih memandang para pengikut sebagai rekanan untuk diberdayakan.

- Mampu mendefinisikan dan secara jelas mengekspresikan suatu ide tentang masa depan bagi suatu kelompok atau organisasi dalam dua sisi - konsep dan tindakan - seperti berbagai tujuan jangka panjang berdasarkan berbagai nilai dan keyakinan inti organisasi.

- Mampu mengembangkan dan mendukung berbagai nilai dan keyakinan inti organisasi di antara anggota organisasi. 
Hipotesis 5 tidak didukung $(\gamma=0,447 ; p>$ 0,05). Hal ini menunjukkan bahwa kepemimpinan transaksional tidak memengaruhi kinerja kerja secara positif. Hasil temuan ini tidak mengkonfirmasi beberapa studi sebelumnya (Bass et al., 2003; Pradana, Sunuharyo \& Hamid, 2013; Yang et al., 2013) yang juga mengatakan bahwa kepemimpinan transaksional memengaruhi kinerja kerja secara positif. Hasil temuan ini tidak didukung karena gaya kepemimpinan transaksional memusatkan perhatiannya pada transaksi interpersonal antara atasan dengan bawahan yang melibatkan hubungan pertukaran. Pertukaran tersebut didasarkan pada kesepakatan mengenai tugas yang dilaksanakan dan penghargaan (reward) atas pemenuhan tugas tersebut (Sonni, 2013). Hasil temuan ini mengkonfirmasi beberapa studi lain (Handajani, 2007; Sonni, 2013) yang juga mengatakan bahwa kepemimpinan transaksional tidak memengaruhi kinerja kerja secara positif.

\section{Model Hasil Penelitian}

Berikut ini adalah model hubungan antara kepemimpinan transformasional, kepemimpinan transaksional dan kinerja kerja yang dimediasi oleh kerjasama tim.

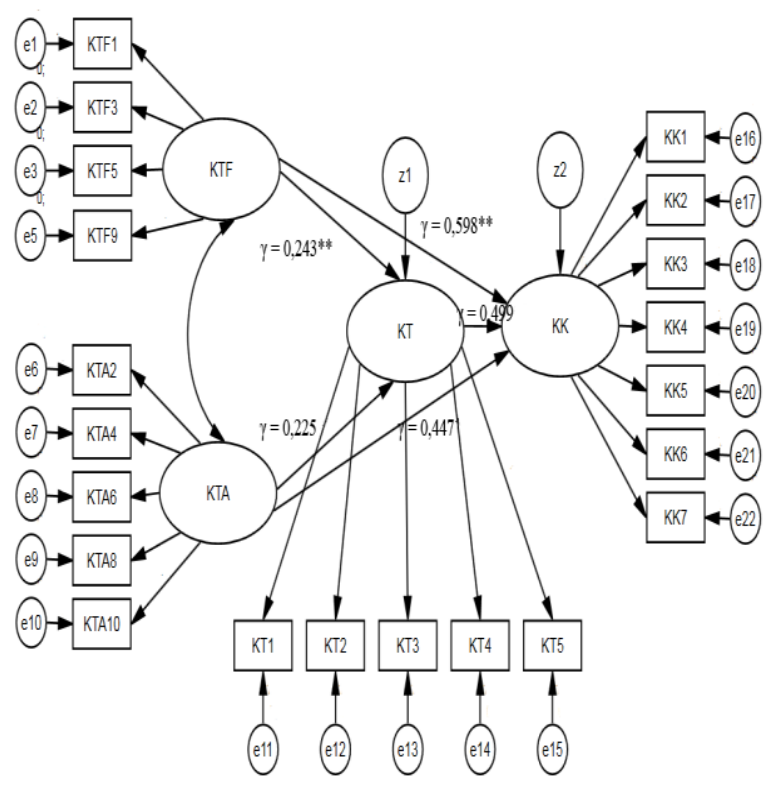

Keterangan:

$K T F=$ Kepemimpinan Transformasional; $K T A=$ Kepemimpinan Transaksional; KT = Kerjasama Tim; $K K=$ Kinerja Kerja $; e=$ error $; z=$ error $* * p<0,01$

\section{Gambar 2 Model Hasil Penelitian}

Sumber: Hasil pengolahan data

\section{SIMPULAN}

Penelitian ini bertujuan untuk menguji tentang kepemimpinan transformasional, kepemimpinan transaksional memengaruhi kinerja kerja secara positif yang dimediasi oleh kerjasama tim. Penelitian ini dilakukan pada 17 (tujuh belas) perusahaan swasta di Kota Bandung yang bergerak di bidang jasa dan retail. Hasil penelitian ini menunjukkan bahwa 2 (dua) dari 5 (lima) hipotesis didukung. Hasil keseluruhan dari penelitian ini menunjukkan bahwa hipotesis 1 didukung ( $\gamma=0,243 ; p<0,05$; Lihat Tabel 4). Artinya, kepemimpinan transformasional memengaruhi kerjasama tim secara positif. Penelitian ini mengkonfirmasi penelitian sebelumnya (Natalius, 2011; Yang et al., 2013) yang juga mengatakan bahwa kepemimpinan transformasional memengaruhi kerjasama tim secara positif. Hipotesis 2 tidak didukung. Artinya, kepemimpinan transaksional tidak memengaruhi kerjasama tim. Penelitian ini tidak mengkonfirmasi penelitian sebelumnya (Natalius, 2011; Yang et al., 2013) yang mengatakan bahwa kepemimpinan transaksional memengaruhi kerjasama tim secara positif. Hipotesis 3 tidak didukung. Artinya, kerjasama tim tidak memengaruhi kinerja kerja. Penelitian ini tidak mengkonfirmasi penelitian sebelumnya (Kotlarsky \& Oshri, 2005; Marpaung, 2014; Poernomo, 2006; Thamain, 2004; Wang et al., 2005; Yang et al., 2013) yang mengatakan bahwa kerjasama tim memengaruhi kinerja kerja secara positif. Hipotesis 4 didukung ( $\gamma=0,598 ; p$ $<0,05$; Lihat Tabel 4). Artinya, kepemimpinan transformasional memengaruhi kinerja kerja secara positif. Penelitian ini mengkonfirmasi penelitian sebelumnya (Bass \& Avolio, 1995; Bass et al., 2003; Judge \& Piccolo,2004; Nugroho, 2011; Pane \& Astuti, 2009; Rakhmawati \& Darmanto, 2014; Yang et al., 2013) yang juga mengatakan bahwa kepemimpinan transformasional memengaruhi kinerja kerja secara positif. Hipotesis 5 tidak didukung. Artinya, kepemimpinan transaksional tidak memengaruhi kinerja kerja. Penelitian ini tidak mengkonfirmasi penelitian sebelumnya (Bass \& Avolio, 1995; Bass et al., 2003; Pradana, Sunuharyo, \& Hamid, 2013; Yang et al., 2013) yang mengatakan bahwa kepemimpinan transaksional memengaruhi kinerja kerja secara positif.

Dalam penelitian ini terdapat hubungan yang relatif tinggi antara kepemimpinan transformasional dan kinerja kerja ( $r=0,757 ; p$ $<0,01)$, terdapat hubungan yang relatif moderat 
antara kepemimpinan transaksional dan kinerja kerja $(r=0,576 ; p<0,01)$, terdapat hubungan yang relatif moderat antara kerjasama tim dan kinerja kerja $(r=0,640 ; p<0,01)$.

\section{KETERBATASAN PENELITIAN}

Terdapat beberapa keterbatasan dalam penelitian ini. Pertama, jumlah sampel terlalu kecil, yakni 121 data. Kedua, teknik pengumpulan data hanya mengandalkan kuesioner survei. Ketiga, studi ini dilakukan pada berbagai industry, sehingga sulit untuk melakukan generalisasi.

\section{SARAN}

Untuk penelitian mendatang, ada beberapa saran yang perlu dipertimbangkan oleh para peneliti yang akan datang. Pertama, pengambilan sampel tidak hanya berkisar 100 (seratus) tapi berkisar antara 200-500 (dua ratus sampai lima ratus). Kedua, untuk penelitian selanjutnya diharapkan tidak hanya menggunakan survei, namun juga menggunakan teknik wawancara dan observasi mengenai perilaku karyawan untuk mengetahui apakah ada intervensi dari pemimpin/rekan kerja atau tidak. Ketiga, sebaiknya studi selanjutnya berfokus pada industry tertentu untuk melakukan generalisasi hasil penelitian. Keempat, para peneliti dapat mempertimbangkan untuk menambahkan beberapa konstuk riset sebagai anteseden kinerja kerja, seperti trust dan komitmen organisasional afektif (Eraut \& Hirst, ca. 2008).

Selain itu ada beberapa saran berupa penerapan bagi pihak manajemen perusahaan. Pertama, para pemimpin dalam perusahaan baik dalam jajaran manajemen tingkat bawah maupun jajaran manajemen tingkat atas perlu meningkatkan perilaku-perilaku kepemimpinan transformasional dengan cara (Rosenbach \& Sashkin, 2007):

1. Communication Leadership - Pemimpin transformasional mendengarkan, memberi perhatian mendalam dan mengarahkan perhatian orang lain melalui komunikasi interpersonal.

2. Credible Leadership - Memiliki integritas yang tinggi.

3. Caring Leadership - Menghormati perasaan orang lain dan peduli terhadap orang lain.

4. Enabling Leadership - Pemimpin berani untuk mengambil risiko.

Lalu, para pemimpin dalam perusahaan baik dalam jajaran manajemen tingkat bawah maupun jajaran manajemen tingkat atas perlu meningkatkan karakteristik-karakteristik kepemimpinan transformasional dalam memimpin para karyawan seperti (Chandra, 2005):

1. Inspiring - Memunculkan kegairahan.

2. Stimulating - Memunculkan minat terhadap hal baru.

3. Coaching - Memberikan bimbingan satu per satu.

4. Team building - Bekerja melalui kelompok kerja.

Dengan meningkatkan berbagai perilaku dan karakteristik pemimpin transformasional tersebut, diharapkan para pemimpin dalam perusahaan dapat membangun hubungan dengan para pengikut dengan lebih baik, mengerti kebutuhan dan kemampuan para pengikut dan dapat menciptakan kinerja kerja yang baik.

Kedua, para pemimpin yang berada baik di jajaran manajemen tingkat bawah dan jajaran manajemen tingkat atas perlu meningkatkan kepemimpinan transaksional dengan cara (Rosenbach \& Sashkin, 2007):

1. Capable Management - memastikan bahwa bawahan memiliki pengetahuan, keterampilan dan sumber daya yang mereka butuhkan untuk melakukan suatu pekerjaan.

2. Reward Equity - Pemimpin akan menepati janji kepada bawahan apa yang mereka mau jika pengikut memberikan kinerja yang baik. Dengan meningkatkan perilaku pemimpin transaksional tersebut, diharapkan para pemimpin dalam perusahaan dapat menepati janji yang telah disepakati dan memicu karyawan untuk menciptakan kinerja yang baik.

Ketiga, para pemimpin yang berada baik di jajaran manajemen tingkat bawah dan jajaran manajemen tingkat atas perlu meningkatkan kerjasama tim dengan cara (Heller, 2001):

- Memastikan semua anggota tim sadar akan tanggung jawab dan tantangan pekerjaan.

- Mendorong anggota tim memberikan kontribusin terbaik dan melaksanakan tugas yang dipercayakan.

- Memantau kerja tim untuk memastikan setiap anggota mengarah kepada tujuan tim.

- Menilai dan menentukan berbagai sasaran pada tingkat yang tepat agar motivasi berlanjut.

- Memastikan tidak terjadinya tumpang tindih tanggung jawab dan tugas tim dan pribadi.

Selain itu, beberapa hal penting yang dapat dilakukan para pemimpin perusahaan untuk 
meningkatkan kerjasama tim adalah (Maxwell, 1995):

1. Menganalisis dinamika tim

Pemimpin tim yang baik bisa memanfaatkan sumber daya manusia yang ada secara optimal, mengerti setiap anggota tim, bagaimana perangainya berubah dalam tim dan bagaimana respon terhadap perkembangan tim.

2. Berkomunikasi secara efektif

Komunikasi yang kuat penting bagi kesehatan tim. Pemimpin harus bisa berkomunikasi secara teratur dan mendorong bawahan agar memiliki komunikasi yang lancar juga.

3. Menyelenggarakan rapat tim

Pemimpin mendorong anggota untuk aktif terlibat dalam rapat, dan memastikan bahwa seluruh anggota dapat mengerti tujuan rapat dan mengerti apa yang diharapkan dari mereka.

4. Membangun jaringan

Pemimpin membangun jaringan dan memanfaatkan hubungan formal dan informal baik di dalam maupun di luar untuk dapatkan dukungan tim.

5. Berbagi informasi di luar tim

Pemimpin tidak bisa hidup sendiri, begitu juga dengan bawahan/rekan kerja. Hubungan dua arah antara tim dengan organisasi induk maupun dengan pendukung eksternal sangat penting. Kerjasama akan terhambat karena tidak ada keterbukaan dalam komunikasi.

6. Berpikir kreatif

Tanpa adanya ide-ide baru, perusahaan tidak akan meraih kesuksesan. Berpikir kreatif adalah tanggung jawab pemimpin, bawahan/rekan kerja, dan seluruh karyawan yang berada di dalam satu perusahaan. Pemimpin membantu mengembangkan dan lebih banyak berlatih.

7. Menangani masalah bersama

Kesetiaan antar anggota tim perlu dibangun sehingga semua masalah, baik pribadi, pekerjaan atau prosedural ditangani sebelum merusak semangat kebersamaan tim.

8. Memperbaiki standar tim

Tim yang ingin meningkat harus belajar menentukan tugas sendiri, mengatasi masalah, setuju penyelesaian dan melaksanakan keputusan mereka dengan percaya diri.

Keempat, para pemimpin yang berada baik di jajaran manajemen tingkat bawah dan jajaran manajemen tingkat atas perlu meningkatkan kinerja kerja dengan cara komunikasi yang baik dengan bawahan ataupun rekan kerja, komunikasi yang baik akan menimbulkan persamaan pada persepsi, jadi tidak akan ada salah paham untuk mengerjakan suatu tugas. Selain itu dengan feedback untuk karyawan tetap termotivasi (Winarno, 2012).

\section{REFERENSI}

Avolio, B. J., Bass, B. M. \& Jung, D. I. (1999). Re-examining the components of transformational and transactional leadership using the multifactor leadership questionnaire. Journal of Occupational and Organizational Psychology, 72, 441-462. Tersedia onlinelibrary.wiley.com/doi/10.1348.

Diakses pada 28 September 2014.

Avolio, B. J., Bass, B. M., Jung, D. I. \& Berson, Y. (2003). Predicting unit performance by assessing transformational and transactional leadership. Journal of Applied Psychology, 88, 207-218. Tersedia pada http://.apa.org/pubs/.../apl-882207.pdf.

Diakses pada 27 November 2014.

Babin, B. J. \& Boles, J. S. (1998). Employee behavior in a service environment: A model and test of potential differences between men and women. Journal of Marketing, 62(April), 77-91.

Bachtiar, H. (2004). Aspek legal kredit sindikasi. Jakarta: PT Raja Grafindo Persada.

Bass, B. M. \& Avolio, B. J. (1990). The implication of transactional and transformational leadership for individual, team, and organizational develompment. Research in Organizational Change and Development, 231-272.

Bass, B. M. (1990). From transactional to transformational leadership: Learning to share the vision. Organizational Dynamics, 18 (3), 19-31.

Bass, B. M. \& Avolio, B. J. (1995). Multifactor leadership questionnaire leader form: $5 x$ short. California: Mind Garden.

Bass, B. M. \& Avolio, B. J. (2002). Multifactor leadership questionnaire feedback report. MLQ Pty, Ltd. Melbourne, 1-43.

Bass, B. M., Avolio, B. J., Jung, D. I., \& Berson, Y. (2003). Predicting unit performance by assessing transformational and transactional leadership. Journal of Applied Psychology, 88(2), 207-218).

Caillier, J. (2010). Citizen Trust, Political Corruption, and Voting Behavior: 
Connecting the Dots. Journal of Politics and Policy, 38(5), 1015-1035. doi: 10.1111/j.1747-1346.2010.00267.x.

Catchpole, K., Mishra, A., Handa, A., \& McCulloch, P. (2008). Teamwork and error in the operating room: Analysis of skills and roles. Journal of Annals of surgery, 247(4), 669-706.

Chandra, R. I. (2005). Seri kepemimpinan: Landasan pacu kepemimpinan. Yogyakarta: PT Gloria Usaha Mulia (GUM).

Cummings, T. G. \& Worley, C. G. (2005). Organization development and change. $8^{\text {th }}$ Edition. USA: Thompson, South-Western.

Eraut, M. \& Hirst, W. (ca. 2008). The significance of workplace of learning for individuals, groups, and organizations. Oxford \& Cardiff Universities: Economic \& Social Research Council, 1-97.

Davies, K. (2005). Human behavior at work organizatonal behavior. New Delhi: McGraw-Hill.

Engestrom, Y., Brown, K., Christopher, L.C., \& Gregory, J. (1997). Coordination, cooperation and communication in the courts: Expansive transitions in legal work. Journal of Management. Tersedia pada http://communication.ucsd.edu. Diakses pada 8 Oktober 2014.

Giri, V. N. \& Kumar, B. P. (2010). Assessing the Impact of Organizational Communication on Job Satisfaction and Job Performance. Journal of psychological, 55(2),137-143. doi: 10.1007/s12646-010-0013-6.

Hair, Jr., J. F., Anderson, R. E., Tatham, R. L. \& Black, W. C. (1998). Multivariate data analysis. 5th Edition, NJ: Prentice-Hall International, Inc.

Handajani, S. (2007). Kajian tentang pengaruh gaya kepemimpinan transaksional dan transformasional terhadap kinerja pegawai PDAM kota Malang. Tugas akhir yang tidak dipublikasikan. Widyaswara Utama Surabaya.

Harianti, A.., Veronica, M. S., Nur., Setiawan, S., \& Iskandar, D. (2012). Statistika II. Yogyakarta: Andi Offset.

Hartog, D. N. D. \& Koopman, P. L. (2011). Leadership in Organizations. Journal of work organization and psychology, 2.

Heller, R. (2001). Essential manager: Managing teams. Jakarta: Penerbit Dian Rakyat.

Indrapradja, F. (2014). Kepemimpinan Transformasional (Transformational leadership) [On-line]. Tersedia pada https://www.kompasiana.com/indrapr adja/54f7cb76a33311be208b4a4a/kep emimpinan-transformasional-

transformational-leadership. Diakses pada 30 Oktober 2018.

Judge, T. A. \& Piccolo, R. F. (2004). Transformational and transactional leadership: A meta-analytic test of their relative validity. Journal of Applied Psychology, 89(5), 755-768. Tersedia pada http://r.search.yahoo.com/_ylt= AwrxhWpJTNhb6n8AQ1X3RQx.;_ylu=X3 oDMTBycWJpM21vBGNvbG8Dc2czBHB vcwMxBHZ0aWQDBHNlYwNzcg-$/ \mathrm{RV}=2 / \mathrm{RE}=1540930761 /$

$\mathrm{RO}=10 / \mathrm{RU}=\mathrm{http} \% 3 \mathrm{a} \% 2 \mathrm{f} \% 2 \mathrm{ftimothy}-$ judge.com\%2fTA-TF\%2520Paper-JAP\%2520published.pdf $/ \mathrm{RK}=2 / \mathrm{RS}=$ wssXu HcgDIVxo2_1ZNd130zeeCY-.

Kark, R., Shamir, B., \& Chen, G. (2003). The two faces of transformational leadership: Empowerment and dependency. Journal of Applied Psychology, 88(2), 246-255.

Keegan, A. E. \& Hartog, D. N. D. (November 2004). Transformational leadership in a project-based environment: A comparative study of the leadership styles of project managers and line managers. International Journal of Project Management, 22(8), 609617. doi: 10.1016/j.ijproman.2004.05.005.

Kendra, K. \& Taplin, L.J. (2004). Project success. A cultural framework. Project Management Journal, 35(1), 30-45.

Kotlarsky, J. \& Oshri, I. (2005). Social ties, knowledge sharing and successful collaboration in globally distributed system development projects. European Journal of Information System, 14, 37-48. http://r.search.yahoo.com/_ylt=AwrxhWq4 SthbISoAtBH3RQx.; ylu=X3oDMTBycWJ pM21vBGNvbG8Dc2czBHBvcwMxBHZ0 aWQDBHNlYwNzcg--

$/ \mathrm{RV}=2 / \mathrm{RE}=1540930361 / \mathrm{RO}=10 / \mathrm{RU}=\mathrm{http} \%$ 3a\%2f\%2fjuliakotlarsky.com\%2fKotlarsky _and_Oshri_EJIS_2005.pdf/RK=2/RS=Goi B48ymzJVBeQJDMr25X6Sjb5k- . Diakses pada 30 Oktober 2018

Kouzes, J. M. \& Posner, B. Z. (2016). Learning leadership: The 5 fundamentals of becoming an exemplary leader. San Francisco, CA: Pfeiffer.

Lai, A. (2011). Transformational-transactional leadership theory. 2011 AHS Capstone Projects. Paper 17. Tersedia pada 
http://digitalcommons.olin.edu/ahs_capston e_2011/17. Diakses pada 5 September 2018.

Lurie, S., Schultz, S., \& Lamanna, G. (2011). Assessing teamwork: A reliable fivequestion survey. Family Medicine, 43(10), 731-734.

Marpaung, M. (2014). Pengaruh kepemimpinan dan teamwork terhadap kinerja karyawan di Koperasi Sekjen Kemdikbud Senayan Jakarta. Jurnal Ilmiah Widya, 2(1), 33-40.

Mathis, R. \& Jackson. (2001). Manajemen sumber daya manusia. Edisi 4. Jakarta: Salemba Empat.

Maxwell, J. (1995). Developing the leaders around you. Nashville, Tennessee: Thomas Nelson, Inc.

Maxwell, J. (2018). Developing the leader within you 2.0. USA: Harper Collins Leadership, an imprint of HarperCollins.

Natalius, F. (2011). Analisa kepemimpinan transaksional dan transformasional untuk meningkatkan kerjasama tim dan kinerja waktu proyek. Tersedia pada lib.ui.ac.id/file?file=digital/20295997-

T29931-Frans\%20Natalius.pdf. Diakses pada 1 Maret 2015.

Nonose, K., Kanno, T., \& Furuta, K. (2012). A team cognition model derived from an analysis of reflection on cooperation. Cognition, Technology \& Work, 14(1), 83-92. doi: 10.1007/s10111-011-0179-2. Diakses pada 30 Oktober 2018.

Noviansyah. (2011). Pengaruh Stres Kerja dan Motivasi Kerja Terhadap Kinerja Kerja pada PT. Perkebunan Minanga Ogan Baturaja. Tersedia pada tappdf.com/read/3735-pengaruh-stres-kerjadan-motivasi-kerja-terhadap-kinerja.

Diakses pada 19 April 2017.

Nugroho, D.A. (2011). Pengaruh Budaya Organisasi dan Gaya Kepemimpinan Transaksional terhadap Komitmen Organisasi dan Kinerja Pegawai. Jurnal of Manajemen dan Bisnis, 1 (2), 167-176.

O'Leary, E. (2001). Kepemimpinan. Edisi Pertama. Yogyakarta: Andi.

Pane, J. \& Astuti, S. (2009). Pengaruh budaya organisasi, kepemimpinan

Transformasional, dan kompensasi Terhadap kinerja karyawan. Jurnal telaah manajemen, 6(1), 67-85. Tersedia pada http://unisbank.ac.id/ojs/index.php/fe5/articl e/.../73. Diakses pada 28 November 2014.

Poernomo, E. (2006). Pengaruh Kreativitas dan Kerjasama Tim Terhadap Kinerja Manajer
Pada PT. Jesslynk Cakes Indonesia Cabang Surabaya, Adm. Bisnis UPN Veteran Jawa Timur. Jurnal Ilmu-Ilmu Ekonomi. 6 (2).

Pradana, M., Sunuharyo, B. S., \& Hamid, J. (2013). Pengaruh Gaya Kepemimpinan Transaksional dan Transformasional terhadap Kinerja Karyawan. Jurnal Administrasi Bisnis, 4(1), 1-11. Tersedia pada binus.ac.id/ecolls/.../2013-2. Diakses pada 28 November 2014.

Pushpakumari, M. D. (2008). The Impact of Job Satisfaction on Job Performance. Tersedia pada

202.11.2.113/SEBM/ronso/no9_1/08_PUS HPAKUMARI.pdf.

Rakhmawati, D. \& Darmanto, S. (2014). Pengaruh gaya kepemimpinan transformasional, kepercayaan, dan kerjasama tim terhadap komitmen organisasi untuk meningkatkan kinerja karyawan. Jurnal Media Ekonomi dan Manajemen, 29 (1), 83-96. Tersedia pada ejournal.ekonomiuntagsmg.ac.id. Diakses pada 1 Desember 2014.

Rantika, R., \& Sunjoyo. (2012). Pengaruh konflik kerja-keluarga terhadap komitmen organisasional yang dimediasi oleh kepuasan kerja pada profesi perawat di Rumah Sakit Umum Daerah (RSUD) Dr. Moewardi Surakarta. Laporan riset yang tidak dipublikasikan. Fakultas Ekonomi Jurusan Manajemen Universitas Kristen Maranatha Bandung.

Robbins, S.P. \& Judge, T.A. (2008). Perilaku organisasi (Organizational behavior). Edisi 12. Jakarta: Salemba Empat.

Rosenbach, W.E. \& Sashkin, M. (2007). The leadership profile: On becoming a better leader trough leadership that matters. International and Pan-American Copyright Conventions: Vista Larga Drive, Gettysburg. Tersedia pada http://leadingandfollowing.com. Diakses pada 26 Februari 2015.

Santoso, S. (2006). Seri solusi bisnis berbasis IT: Menggunakan SPSS untuk statistic parametrik. Jakarta: Penerbit PT Elex Media Komputindo.

Sashkin, M. \& Sashkin, M.G. (2003). Leadership that matters: The critical factors for making a difference in people's lives and organizations' success. San Francisco: Berrett-Koehler Publisers, Inc.

Sekaran, U. \& Bougie, R. (2010). Research methods for business: A skill building 
approach. $5^{\text {th }}$ Edition. West Sussex, UK: John Wiley \& Son Ltd.

Seltzer, J. \& Bass, B. M. (1990). Transformational Leadership: Beyond Initiation and Consideration. Journal of Management, 16(4): 693-70.

Simamora, H. (2004). Manajemen Sumber daya manusia. Edisi 2. Yogyakarta.

Sonni, J. A. (2013). Pengaruh gaya kepemimpinan transformasional dan transaksional terhadap kinerja organisasi dengan budaya organisasi sebagai variabel pemoderasi: Studi empiris pada perusahaan perbankan di kota Padang. Artikel yang tidak dipublikasikan, Universitas Negeri Padang.

Sunjoyo. (2013). Dampak kepemimpinan transaksional, transformasional, dan melayani terhadap kinerja kerja. Proceedings Seminar \& Call For Paper Forum Manajemen Indonesia ke-5 (FMI-5). Kalimantan Barat, Pontianak: Bank Indonesia dan Mercure Hotel, p. 200. Tersedia pada sunjoyo.lecturer.maranatha.edu. Diakses pada 8 Januari 2015.

Thamain, H. (2004). Linkages of project environment to performance: Lessons for team leadership. International Journal of Project Management, 22(7), 533-544.

Vidal, L. \& Marle, F. (2008). Handbook on project management and scheduling. Tersedia pada https://books.google.co.id/books?isbn=3319 059157.

Wang, E., Chou, H. W., \& Jiang, J. (2005). The impacts of charismatic leadership style on team cohesiveness and overall performance during ERP implementation. International Journal of Project Management, 23(3), 173180.

Wang, S. \& He, Y. (2008). Compensating nondedicated cross-functional teams. Journal of organization science, $753-765$. doi: 10.1287/orsc.1070.0351.

Winarno, T. (2012). Pengaruh lingkungan kerja dan gaya kepemimpinan terhadap motivasi kerja dan implikasinya terhadap kinerja karyawan di Di Perguruan Tinggi Swasta STIMAR-AMNI Semarang. Jurnal Fokus Ekonomi, 7(1), 1-19.

Yang, L., Wu, K., \& Huang, C. (2013). Validation of a model measuring the effect of a project manager's leadership style on project performance. Journal of Civil
Engineering, $17(2), \quad 271-280 . \quad$ Doi: 10.1007/s12205-013-1489-0. 
Jurnal Manajemen Maranatha — Vol. 18 Nomor 2, Mei (2019) 